\title{
Loss of NLRP3 increases bacterial cystitis via IRAKM
}

\author{
Jie Sun", Lei Xia", Yubing Peng \\ Department of Urology, RenJi Hospital Affiliated to Shanghai Jiaotong University School of Medicine, Shanghai, China \\ Contributions: (I) Conception and design: All authors; (II) Administrative support: Y Peng; (III) Provision of study materials or patients: All authors; \\ (IV) Collection and assembly of data: All authors; (V) Data analysis and interpretation: All authors; (VI) Manuscript writing: All authors; (VII) Final \\ approval of manuscript: All authors. \\ \#These authors contributed equally to this work. \\ Correspondence to: Yubing Peng. Department of Urology, RenJi Hospital Affiliated to Shanghai Jiaotong University School of Medicine, 630 \\ Dongfang Road, Shanghai 200127, China. Email: pybkzt@163.com.
}

\begin{abstract}
Background: We attempted to characterize the molecular mechanisms that underpin urinary tract infections using a mouse model of cystitis induced by bacterial infection in a background of NOD-, LRRand PYD domains-containing protein (NLRP3) deficiency.

Methods: Male NLRP3 knockout $\left(\mathrm{NLRP}^{-/}\right)$and control mice (12 weeks old) were intraurethrally inoculated with $2 \times 10^{8}$ Escherichia coli (E. coli) and euthanized 1, 3, and 7 days later to assess the degree of bladder infection. Immunohistochemical detection of NLRP3 and interleukin-1 receptor-associated kinase M (IRAKM) was performed. Quantitative PCR analysis was performed to analyze the expression of interleukin (IL)-1 $\beta$ and tumor necrosis factor (TNF)- $\alpha$.

Results: Bladder infection was observed in control mice 1 day after inoculation with $E$. coli. The infection had disappeared by day 7. IL-1 $\beta$ and TNF- $\alpha$ levels were lower 1 day after injection but higher on days 3 and 7 in the NLRP3 ${ }^{-/}$group compared with the control mice $(\mathrm{P}<0.05)$. Expression of NLRP3 and IRAKM in wild-type (WT) group were significantly decreased 1 day post infection, and by day 7 were increased back to similar level on day 0 . On the contrary, in the $\mathrm{NLRP}^{-/-}$group, IRAKM was significantly lower than WT mice on day 0 and were significantly decreased by day 7 .

Conclusions: Deficiency of NLRP3 expression in $\mathrm{NLRP}^{-/-}$mice contributes to the pathogenesis of chronic inflammation associated with cystitis through IRAKM.
\end{abstract}

Keywords: Cystitis; NOD-, LRR- and PYD domains-containing protein (NLRP3); interleukin-1 receptorassociated kinase $M$ (IRAKM)

Submitted Jan 07, 2022. Accepted for publication Feb 18, 2022.

doi: $10.21037 /$ tau-22-67

View this article at: https://dx.doi.org/10.21037/tau-22-67

\section{Introduction}

Urinary tract infections (UTIs) are a common cause of clinical infectious disease. Pathogenic Escherichia coli (E. coli) is the most common pathogen causing UTIs, accounting for $80 \%$ to $90 \%$ of community-acquired UTIs and $40 \%$ to $50 \%$ of hospital UTIs (1). Approximately $95 \%$ of UTIs in the clinic are simple bladder infections (cystitis). UTIs predominantly occur in individuals with normal anatomy. These infections are characterized by urinary tract burning, frequent urination, urgency, and discomfort in the suprapubic area. About $40 \%$ of women and $12 \%$ of men have at least one UTI in their lifetime (2). Besides E. coli (86\%), Staphylococcus saprophyticus (4\%) is a common pathogen in UTI (3). Innate immunity defects increase susceptibility to UTI, including polymorphisms in pathways like Toll-like receptor 1/2/4 (TLR 1/2/4), C-X-C chemokine receptor 1/2 (CXCR1/2), C-X-C motif chemokine ligand 8 (CXCL8) and interferon regulatory factor 3 (IRF3), etc. The high recurrence rate of UTIs, which may be partly due to endogenous recurrence rather than secondary infection with new strains, is reportedly 
due to defects in the host's memory immune response. Bladder mast cells exhibit extensive immunosuppressive transcriptional activity as a consequence of UTIs. This phenomenon results in the secretion of IL-10 and the inhibition of humoral immune responses in the bladder (4). Inflammatory activation of NOD-, LRR- and pyrin domain-containing protein 3 (NLRP3) has been shown to be an important mediator of cyclophosphamide-induced bladder inflammation, and some studies have also shown that human bladder epithelial cells express high levels of NLRP3 (5). Currently, there is insufficient evidence to suggest that NLRP3 has an effect on the onset of bladder pain syndrome/interstitial cystitis (BPS/IC) (6).

The NLRP 3 inflammasome is a group of cytosolic protein complexes that mediate host immune responses to microbial infections and cell damage (7). NLRP3 inflammatory bodies induce procaspase- 1 proteolysis to activate caspase- 1 , which subsequently converts the cytokine precursors pro-IL- $1 \beta$ and pro-IL-18 into mature active IL$1 \beta$ and IL-18, respectively (8). The active form of IL- $1 \beta$ is a pro-inflammatory mediator of many immune responses, including the chemotactic response of innate immune cells and the regulation of adaptive immune cells. The activation of NLRP 3 inflammatory bodies requires the participation of dual signals, which are divided into 2 stages: priming and activation. Expression of NLRP3 is induced by priming with microbial components such as toll-like receptor (TLR) ligands, endogenous molecules, tumor necrosis factor (TNF), or IL-1 $\beta$ through the activation of nuclear factor kappa B (NF- $\mathrm{B})$. Priming positively regulates the NLRP3 inflammasome through the induction of NLRP3 expression. The structural diversity of NLRP3 suggests that it is less likely to interact with activators. It is possible that NLRP3 may respond to signaling pathways that are induced by NLRP3 activators (9).

We observed that NLRP3 gene-deficient mice exhibited a specific inflammatory response in a bacterial cystitis model established following the inoculation of mouse bladders with conventional $E$. coli ATCC 25922. We believe that this model will help scientists to better understand the molecular mechanisms that underpin bacterial cystitis. We used immunohistochemistry and qPCR to detect changes in the inflammatory pathway triggered by prostatitis in NLRP3-deficient mice. Finally, we attempted to confirm a possible role for NLRP3 in bacterial cystitis. We present the following article in accordance with the ARRIVE reporting checklist (available at https://tau.amegroups.com/ article/view/10.21037/tau-22-67/rc).

\section{Methods}

\section{Bacterial culture and animal surgery}

$\mathrm{NLRP}^{-/-}$mice (B6. 129S6-Nlrp3tm1Bhk/J, stock no. 021302) were purchased from the Jackson Laboratory (Bar Harbor, ME, USA). Bacterial cystitis was established as previously described by transurethral intravesical injection of the mice with E. coli (Difco Laboratories, Detroit, MI, USA) (10). Briefly, E. coli cells $\left(1 \times 10^{8} / \mathrm{mL}, 20 \mu \mathrm{L}\right.$ containing $2 \times 10^{6}$ E. coli per mouse) were resuspended in sterile phosphate-buffered saline and transurethrally instilled into $\mathrm{NLRP}^{-/-}$and wild-type (WT) control mice under isoflurane anesthesia. The urethral syringe consisted of a polyethylene tube covering a 30-G hypodermic needle. The catheter was mounted on a sterile $1 \mathrm{~mL}$ disposable syringe containing E. coli. The E. coli strain was inoculated in sterile Luria-Bertani (LB) medium (10 g/L glucose, $10 \mathrm{~g} / \mathrm{L}$ peptone, $5 \mathrm{~g} / \mathrm{L}$ yeast, $10 \mathrm{~g} / \mathrm{L} \mathrm{NaCl}$, and $\mathrm{pH}=7$ ) following resuscitation. After culturing for 24 to $48 \mathrm{~h}$ in a constant temperature incubator at $30^{\circ} \mathrm{C}$, passaging was carried out. After 3 passages, the bacteria were harvested and washed with physiological saline solution (PSS), and the bacteria were subsequently suspended in PSS (11). An appropriate concentration of the bacterial suspension in PSS was used as an inoculum. Mice were anesthetized with intraperitoneal injection of sodium pentobarbital $(50 \mathrm{mg} / \mathrm{kg})(12)$. After the distal end of the catheter was inserted into the urethra of male mice to a distance length of approximately 0.6 to $0.8 \mathrm{~cm}$, the inoculated bacteria were directly injected and deposited into the bladder (13). The inoculated mice were euthanized 1, 3, and 7 days following inoculation. Finally, inoculated mice were placed in the supine position, and the lower abdomen was dissected to expose the bladder. The bladder tissue was collected and analyzed. No criteria were used for excluding animals during the experiment, and no data were excluded during the analysis. The present study was approved by the Research and Animal Ethics Association of Shanghai Jiao Tong University [license No. HKDL(2016)149], in accordance with the institutional guidelines for the care and use of laboratory animals. Animal experiments were done in Shanghai Jiao Tong University. A protocol was prepared before the study without registration.

\section{Determination of bacterial loads in mice}

The bacterial loads in the bladder cavity of mice were determined using standard plate counts (SPC) and in vivo bioluminescence imaging (BLI) methods $(14,15)$. The mice 
were inoculated via a transurethral intravesical injection with $2 \times 10^{6}$ colony-forming unit (CFU) of bioluminescent E. coli $(20 \mu \mathrm{L}$ per mouse). Bioluminescent signals from the infection site were recorded at 0 and $72 \mathrm{~h}$ post-infection using the IVIS Lumina II Imaging System (PerkinElmer, MA, USA). The signal was quantified as total photon emission within a designated region of interest using Living Image Software version 3.0 (Caliper Life Sciences, Hopkinton, MA, USA).

\section{Histological analysis and immunobistochemistry}

For histological analysis, dissected bladder tissue was fixed overnight with $10 \%$ buffered neutral formalin and then embedded in paraffin and sectioned at a thickness of $4 \mu \mathrm{m}$. Sections were stained with hematoxylin and eosin $(\mathrm{H} \& \mathrm{E})$ to visualize inflammation and pathological changes. The degree of inflammatory cell infiltration was evaluated by H\&E staining. NLRP3 (cat. No. ab214185, Abcam, Cambridge, MA, USA) and interleukin-1 receptorassociated kinase M (IRAKM; cat. no. ab8116, Abcam) levels were detected by immunohistochemistry. Immunoreactivity was quantified using Image-Pro Plus v.6.0 software (Media Cybernetics, Bethesda, MD, USA).

\section{qRT-PCR analysis}

Total RNA ( $1 \mu \mathrm{g})$ was isolated from tissue samples using TRIzol reagent (Invitrogen, Carlsbad, CA, USA) according to the manufacturer's instructions. Reverse transcription (RT) was performed using TaqMan reagents (Applied Biosystems, Foster City, CA, USA). RT was carried out at $42{ }^{\circ} \mathrm{C}$ for 60 minutes followed by inactivation at $94{ }^{\circ} \mathrm{C}$ for 5 minutes, and immediate cooling at $4^{\circ} \mathrm{C}$ (16). qRT-PCR was carried out using SYBR Green Universal Master Mix on a Step One Plus Real-Time PCR system (Applied Biosystems). The relative quantity of target mRNAs was determined with the comparative cycle threshold method and normalized to human cyclophilin or mouse glyceraldehyde 3-phosphate (17). The primer sequences were as follows (18): mouse TNF- $\alpha$, 5'-CTGTAGCCCACGTCGTAGC-3' and 5'-TTGAGATCCATGCCGTTG-3'; mouse IL$1 \beta, 5$ ' -TGTAATGAAAGACGGCACACC-3 ' and 5'-TCTTCTTTGGGTATTGCTTGG-3'. The qPCR reactions were carried out in a final volume of $10 \mu \mathrm{L}$ with each reaction containing $200 \mu \mathrm{M}$ dNTPs and $2 \mu \mathrm{M}$ of each primer. The reactions were performed at $95{ }^{\circ} \mathrm{C}$ for 2 minutes followed by 40 cycles of $95^{\circ} \mathrm{C}$ for 15 seconds, $55^{\circ} \mathrm{C}$ for 20 seconds, and $72{ }^{\circ} \mathrm{C}$ for 45 seconds. Relative gene expression was calculated from the $\mathrm{Ct}$ value using the $\Delta \Delta \mathrm{Ct}$ method (19).

\section{Statistical analysis}

Data were analyzed using Prism v.7.0 software (GraphPad Inc., La Jolla, CA, USA). The IOD SUM function of Integrated Performance Primitives (IPP) 6.0 (Intel, CA, USA) was used to quantify the expression of NLRP3 and IRAKM evaluated by immunohistochemistry. Differences between groups were assessed by one-way analysis of variance (ANOVA) and Bonferroni's multiple comparisons test. $\mathrm{P}<0.05$ was considered statistically significant.

\section{Results}

\section{Histological examination of bladder tissue in cystitis model mice}

There was no significant bladder histological difference in $\mathrm{H} \& \mathrm{E}$ staining between WT and $\mathrm{NLRP}^{-/-}$group at day 0 (Figure $1 A, 1 B$ ). Accentuated bladder pathology was more obvious in WT mice 1 day after $E$. coli injection than in the $\mathrm{NLRP}^{-/-}$group (Figure $1 C, 1 D$ ). On day 3, infection in WT mice started to decrease (Figure $1 E$ ), while $\mathrm{NLRP}^{-/-}$mice showed obvious intraepithelial infiltration of bladder mucosa by lymphocytes 3 days after prostate infection (Figure 1F). Lymphocyte infiltration persisted in the $\mathrm{NLRP}^{-/}$group after it was no longer detected in the WT group (Figure $1 G, 1 H$ ). Initially, there was no difference in IL-1 $\beta$ and TNF- $\alpha$ expression between the 2 groups, as determined by qRT-PCR (Figure 1I,17). However, 1 day after infection, both IL-1 $\beta$ (Figure $1 \mathrm{~K}, \mathrm{P}=0.0084$ ) and TNF- $\alpha$ (Figure $1 L, \mathrm{P}=0.0012$ ) were elevated in the WT group compared to $\mathrm{NLRP}^{-/-}$mice, whereas the opposite trend was observed on day $3(\mathrm{P}=0.0003$ and 0.0005 , respectively; Figure $1 M, 1 \mathrm{~N})$. After 7 days, the expression of both cytokines was still higher in mutants, although the difference between the 2 groups was not significant (Figure 1O,1P). These results indicate that NLRP3 ${ }^{-1-}$ mice exhibit a delayed inflammatory response to bacterial infection.

\section{IVIS tracking of E. coli}

IVIS analysis revealed obvious differences in the evacuation of $E$. coli through the urethra after 72 h. E. coli inoculation 
$0 d$
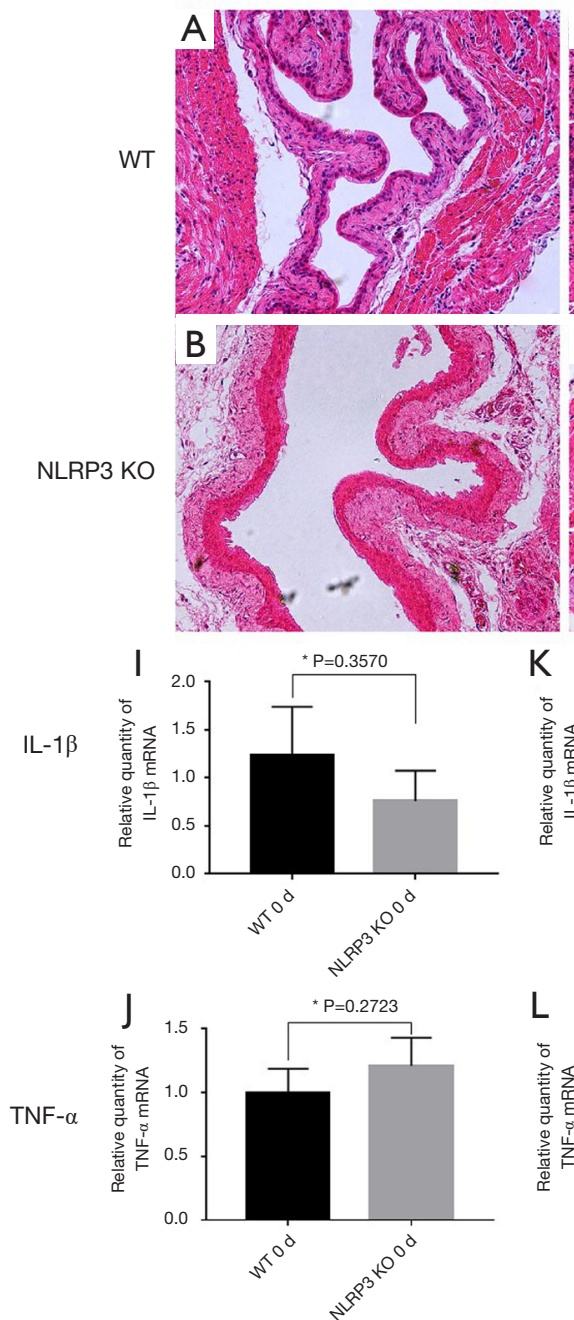

$1 \mathrm{~d}$
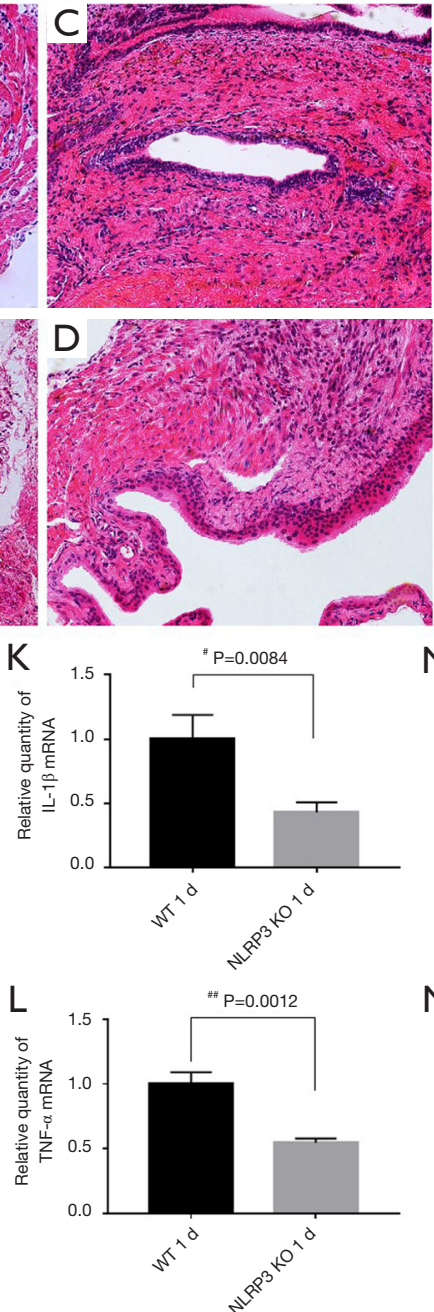

$3 d$
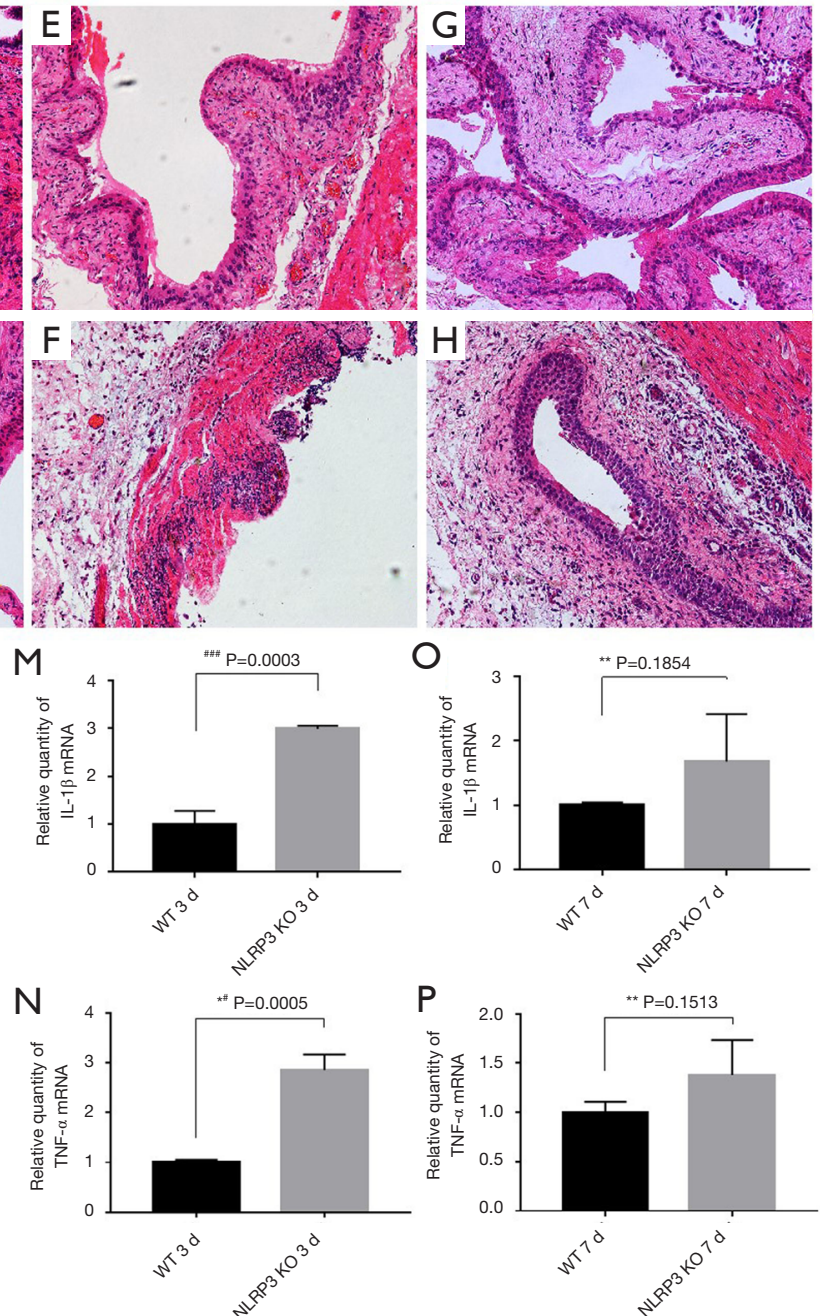
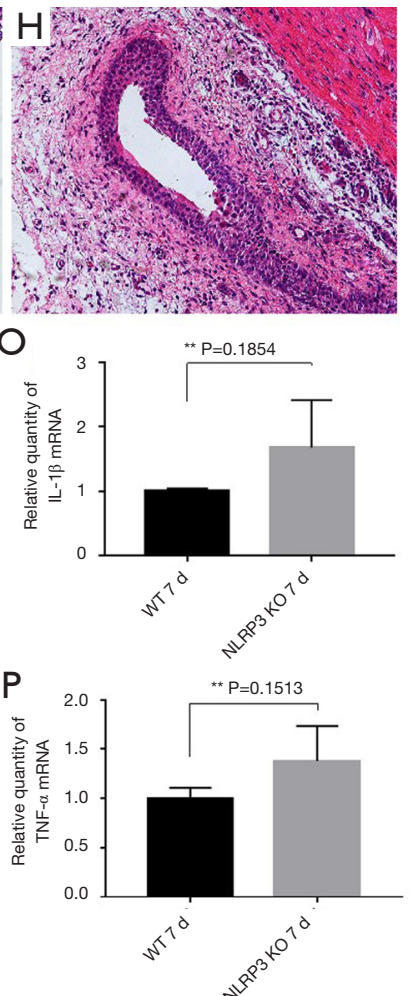

Figure 1 Hematoxylin and eosin (H\&E) staining ( $\times 200)$ of the bladder and qPCR analysis of IL-1 $\beta$ and TNF- $\alpha$ expression. There was no significant bladder histological difference between $\mathrm{WT}$ and $\mathrm{NLRP}^{-/-}$group at day $0(\mathrm{~A}, \mathrm{~B})$. Accentuated bladder pathology was more obvious in WT mice 1 day after E. coli injection than in the $\mathrm{NLRP}^{-/-}$group (C,D). The WT group exhibited an obvious reduction in inflammatory responses until they completely disappeared after 7 days. However, the NLRP3 ${ }^{-/-}$group exhibited a slower and progressively worsening inflammatory response, which was still evident on the 7th postoperative day (E-H). qPCR analysis revealed that there was no significant difference between IL-1 $\beta$ and TNF- $\alpha$ expression (I,J, *, P>0.1). One day after infection, the WT group exhibited significant increases in IL-1 $\beta\left(\mathrm{K},{ }^{\#} \mathrm{P}=0.0004\right)$ and TNF- $\alpha\left(\mathrm{L},{ }^{\# \#}, \mathrm{P}=0.0012\right)$ expression compared with the NLRP3 ${ }^{-/-}$group. Three days after injection

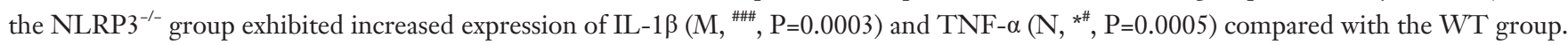
One week after injection there was no significant difference in the expression of IL-1 $\beta$ and TNF- $\alpha$. However, expression of these cytokines was still higher in the $\mathrm{NLRP}^{-/}$group compared with the $\mathrm{WT}$ group $\left(\mathrm{O}, \mathrm{P},{ }^{* *}, \mathrm{P}>0.1\right)$. The $\mathrm{NLRP}^{-/}$group exhibited a relatively slow inflammatory response. WT, wild-type; IL, interleukin; TNF, tumor necrosis factor. 

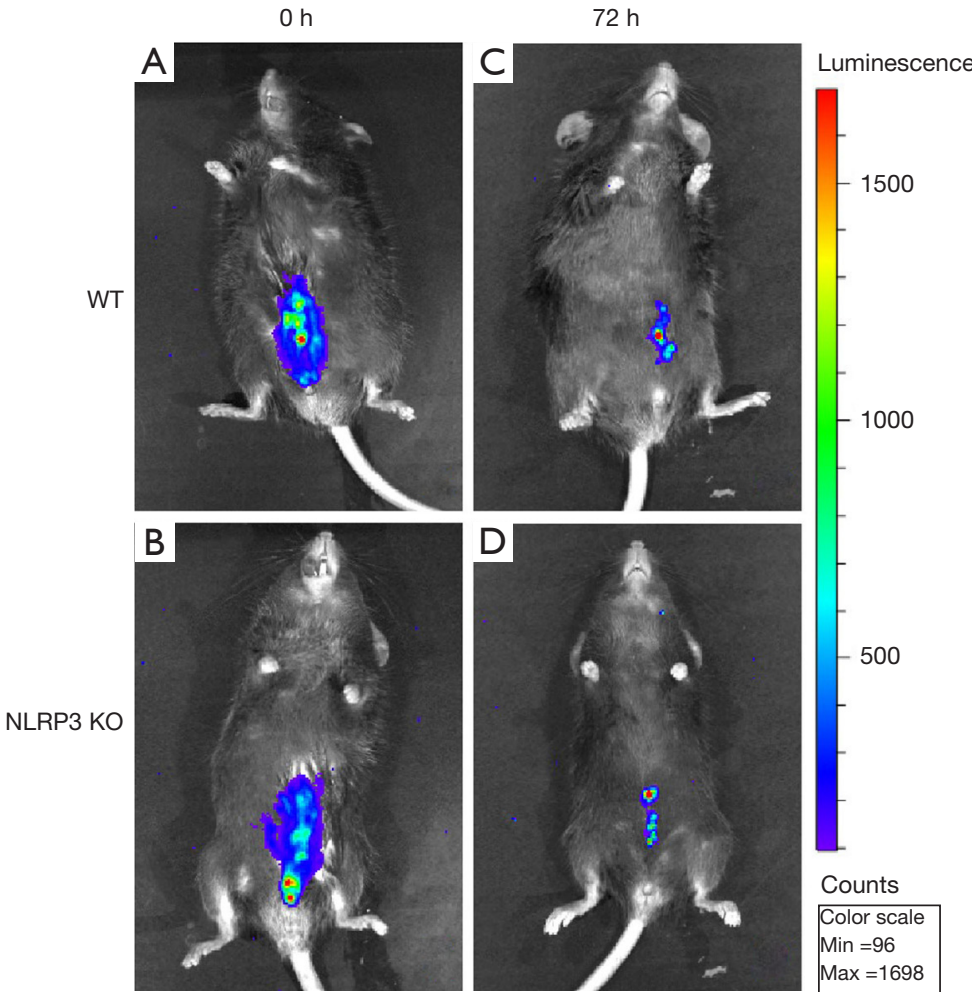

Figure 2 Tracking of bioluminescent E. coli after intravesical injection. E. coli inoculation were detected in both WT (A) and NLRP3 KO (B) group at $0 \mathrm{~h}$. The radiographic performance of both experimental groups was significantly reduced but still detectable after $72 \mathrm{~h}(\mathrm{C}, \mathrm{D})$. There was no significant difference between the NLRP3 ${ }^{-/-}$and control group. E. coli, Escherichia coli; WT, wild-type. NLRP3, NOD-, LRRand PYD domains-containing protein. KO, knockout.

were detected in both WT (Figure 2A) and NLRP3 KO (Figure $2 B$ ) group at $0 \mathrm{~h}$. A limited number of bioluminescent E. coli remained in mice from the WT group after $72 \mathrm{~h}$ (Figure 2C,2D). However, IVIS analysis revealed that the radiographic performance of both experimental groups was significantly reduced but still detectable, confirming that some $E$. coli cells remained in the bladder.

\section{Immunobistochemical detection of inflammatory marker expression in cystitis mice model}

NLRP3 was expressed in the bladder of the WT group at day 0 (Figure $3 A$ ), markedly reduced after 1 day infection $(\mathrm{P}=0.0010$; Figure $3 B)$ and gradually increased at day 3 (Figure $3 C$ ) and day 7 (Figure 3D), which showed no difference compared with the initial value $(\mathrm{P}=0.1438$; Figure $3 E$ ). The alterations in NLRP3 expression were inversely proportional to the degree of inflammation.
A similar trend was observed for IRAKM expression. IRAKM was highly expressed in WT group at day 0 (Figure 4A), and was significantly lower in NLRP3 KO group (Figure $4 B$ ). IRAKM level was decreased 1 day after surgery in WT mice ( $\mathrm{P}=0.026$; Figure $4 C)$ while no change in NLRP3 KO mice (Figure 4D). On day 3, IRAKM expression started to increase in WT group (Figure 4E) and was significantly higher than NLRP3 KO group (Figure $4 F$ ). On day 7, IRAKM expression returned to a similar level to that originally observed in WT group (Figure $4 G$ ), whereas it was significantly downregulated in $\mathrm{NLRP}^{-/-}$mice (Figure 4H,4I).

\section{Discussion}

NLRP3 is a member of the NLR family of proteins that mediate inflammatory responses to microbial infection and cellular damage by inducing the formation of inflammatory 

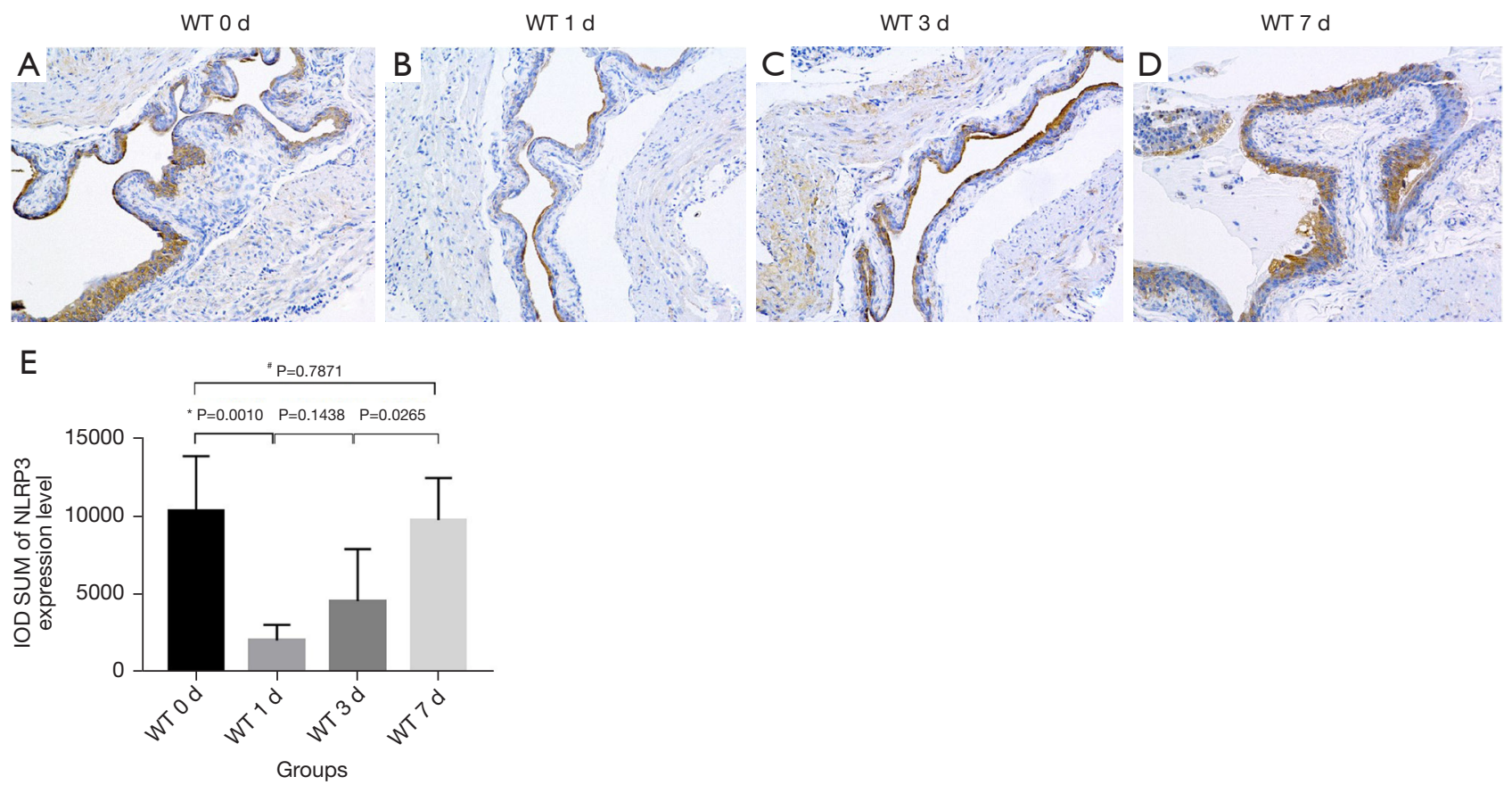

Figure 3 NLRP3 expression of the WT group following IHC $(\times 200)$ and IPP6.0 statistical analyses. NLRP3 expression was significantly altered in W'T mice after intravesical injection. NLRP3 was expressed in the bladder of the W'T group at day 0 (A), which was significantly reduced after 1 day $\left(\mathrm{B}, \mathrm{E},{ }^{*}, \mathrm{P}=0.0010\right.$, IHC $\left.\times 200\right)$. However, the expression gradually increased at day 3 (C) and day 7 (D) until there was no significant difference compared to the initial expression ( $\mathrm{E}$, ,, $\mathrm{P}=0.7871$ ). The change in NLRP3 expression was inversely proportional to the degree of the inflammatory response. WT, wild-type; IHC, immunohistochemistry.

corpuscles (7). The NLRP3 inflammasome activates IL$1 \beta$ through caspase-1 (20). IL-1R and TLR2/IL-1 activate myeloid differentiation primary response 88 (MyD88)/ IRAK/NF- $\mathrm{KB}$ signaling, which is inhibited by IRAKM (21). Thus, during acute inflammation, NLRP3 is positively and negatively correlated with IL-1 $\beta$ and IRAKM expression, respectively.

The results of our study suggest that $\mathrm{NLRP}^{-/-}$mice exhibit a slower inflammatory response than their WT counterparts in a cystitis model. A previous study reported exacerbation of acute cystitis in NLRP $3^{-/}$and $\mathrm{Asc}^{-/}$ mice (22). Our model revealed that NLRP3 knockout alone accentuated bladder pathology while delaying the acute inflammatory response time. We also confirmed a positive relationship between NLRP 3 and IL-1 $\beta$ in the acute stage of $E$. coli-induced cystitis. However, NLRP3 ${ }^{-1-}$ mice showed a gradual reduction of the inflammatory response after the initial phase. In our cystitis model, the inflammatory response in WT mice subsided after 1 week. Bacterial cystitis in $\mathrm{NLRP}^{-/-}$mice was characterized by a slower onset and attenuation of inflammation, which was associated with a negative correlation between NLRP3 and IL-1 $\beta$ levels and a positive correlation between NLRP3 and IRAKM expression. Our results suggest the presence of distinct signaling pathways in $\mathrm{WT}$ and $\mathrm{NLRP}^{-/-}$mice. NLRP3 deletion may result in a gradual upregulation of IL$1 \beta$ and NF- $\kappa B$ following the acute phase of inflammation, implying that NLRP3 has a bidirectional effect in the progression of inflammation, with IRAKM playing a synergistic role.

In summary, the results of our study provide evidence that NLRP3 deficiency contributes to chronic inflammation associated with cystitis. Chronic cystitis is a common disease that is difficult to cure and can often only be treated symptomatically. This is the first study to report that chronic cystitis may be related to defects in traditional inflammation pathways. However, further research is needed to clarify the mechanisms by which NLRP3 deficiency leads to chronic cystitis. Our results indicate that therapeutic strategies targeting the inflammatory response or NLRP3 might be effective for the future treatment of chronic cystitis. 


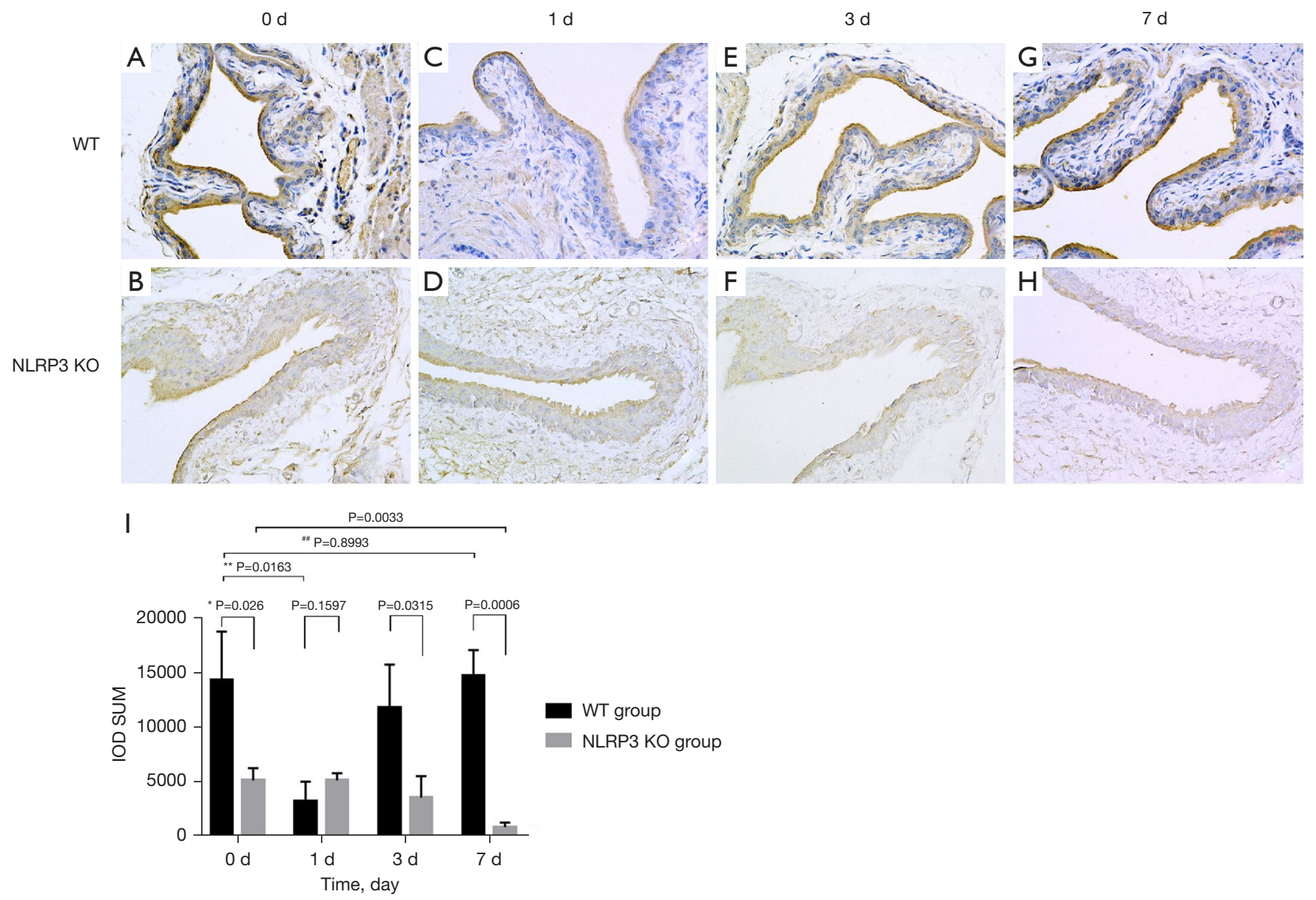

Figure 4 IRAKM expression in mouse cystitis model. IRAKM was highly expressed in WT group at day 0 (A), and was significantly lower in NLRP3 KO group (B). IRAKM expression decreased significantly 1 day after surgery in WT group (C,I, **, $\mathrm{P}=0.0163$, IHC $\times 400)$, but not in NLRP3 KO group (D). In WT mice, IRAKM expression gradually increased on day 3 (E) and returned to normal levels 7 days

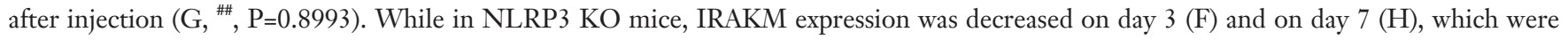
significantly lower compared to the control group (I, *, $\mathrm{P}=0.026$ ). IRAKM positive staining revealed that NLRP3 knockout might cause a positive correlation with the expression of IRAKM. IRAKM, interleukin-1 receptor-associated kinase M; IHC, immunohistochemistry; WT, wild-type; $\mathrm{KO}$, knockout.

\section{Acknowledgments}

Funding: This work was supported by grants from the Shanghai Municipal Health Bureau Scientific Research Project (Grant No. 201840300).

\section{Footnote}

Reporting Checklist: The authors have completed the ARRIVE reporting checklist. Available at https://tau. amegroups.com/article/view/10.21037/tau-22-67/rc
Data Sharing Statement: Available at https://tau.amegroups. com/article/view/10.21037/tau-22-67/dss

Conflicts of Interest: All authors have completed the ICMJE uniform disclosure form (available at https://tau.amegroups. com/article/view/10.21037/tau-22-67/coif). The authors have no conflicts of interest to declare.

Ethical Statement: The authors are accountable for all aspects of the work in ensuring that questions related 
to the accuracy or integrity of any part of the work are appropriately investigated and resolved. The present study was approved by the Research and Animal Ethics Association of Shanghai Jiao Tong University [license No. HKDL(2016)149], in accordance with the institutional guidelines for the care and use of laboratory animals. Animal experiments were done in Shanghai Jiao Tong University.

Open Access Statement: This is an Open Access article distributed in accordance with the Creative Commons Attribution-NonCommercial-NoDerivs 4.0 International License (CC BY-NC-ND 4.0), which permits the noncommercial replication and distribution of the article with the strict proviso that no changes or edits are made and the original work is properly cited (including links to both the formal publication through the relevant DOI and the license). See: https://creativecommons.org/licenses/by-nc-nd/4.0/.

\section{References}

1. Ejrnæs K. Bacterial characteristics of importance for recurrent urinary tract infections caused by Escherichia coli. Dan Med Bull 2011;58:B4187.

2. Foxman B. The epidemiology of urinary tract infection. Nat Rev Urol 2010;7:653-60.

3. Hanlon JT, Perera S, Drinka PJ, et al. The IOU Consensus Recommendations for Empirical Therapy of Cystitis in Nursing Home Residents. J Am Geriatr Soc 2019;67:539-45.

4. Choi HW, Abraham SN. Why Serological Responses during Cystitis are Limited. Pathogens 2016;5:19.

5. Hughes FM Jr, Vivar NP, Kennis JG, et al. Inflammasomes are important mediators of cyclophosphamide-induced bladder inflammation. Am J Physiol Renal Physiol 2014;306:F299-308.

6. Hanno PM, Erickson D, Moldwin R, et al. Diagnosis and treatment of interstitial cystitis/bladder pain syndrome: AUA guideline amendment. J Urol 2015;193:1545-53.

7. Franchi L, Muñoz-Planillo R, Núñez G. Sensing and reacting to microbes through the inflammasomes. Nat Immunol 2012;13:325-32.

8. Martinon F, Burns K, Tschopp J. The inflammasome: a molecular platform triggering activation of inflammatory caspases and processing of proIL-beta. Mol Cell 2002;10:417-26.

9. He Y, Hara H, Núñez G. Mechanism and Regulation of NLRP3 Inflammasome Activation. Trends Biochem Sci
2016;41:1012-21.

10. Shinohara DB, Vaghasia AM, Yu SH, et al. A mouse model of chronic prostatic inflammation using a human prostate cancer-derived isolate of Propionibacterium acnes. Prostate 2013;73:1007-15.

11. Arshi N, Ahmed F, Kumar S, et al. Microwave assisted synthesis of gold nanoparticles and their antibacterial activity against Escherichia coli (E. coli). Current Applied Physics 2011;11:S360-S363.

12. Robichaud A, Stamatiou PB, Jin SL, et al. Deletion of phosphodiesterase 4D in mice shortens alpha(2)adrenoceptor-mediated anesthesia, a behavioral correlate of emesis. J Clin Invest 2002;110:1045-52.

13. Hannan TJ, Hunstad DA. A Murine Model for Escherichia coli Urinary Tract Infection. Methods Mol Biol 2016;1333:159-75.

14. Schachern PA, Tsuprun V, Ferrieri P, et al. Pneumococcal PspA and PspC proteins: potential vaccine candidates for experimental otitis media. Int J Pediatr Otorhinolaryngol 2014;78:1517-21.

15. Albiger B, Sandgren A, Katsuragi H, et al. Myeloid differentiation factor 88-dependent signalling controls bacterial growth during colonization and systemic pneumococcal disease in mice. Cell Microbiol 2005;7:1603-15.

16. Peng YB, Zhou J, Gao Y, et al. Normal prostate-derived stromal cells stimulate prostate cancer development. Cancer Sci 2011;102:1630-5.

17. Sakai A, Koga T, Lim JH, et al. The bacterium, nontypeable Haemophilus influenzae, enhances host antiviral response by inducing Toll-like receptor 7 expression: evidence for negative regulation of host antiviral response by CYLD. FEBS J 2007;274:3655-68.

18. Lee J, Komatsu K, Lee BC, et al. Phosphodiesterase 4B mediates extracellular signal-regulated kinasedependent up-regulation of mucin MUC5AC protein by Streptococcus pneumoniae by inhibiting cAMP-protein kinase A-dependent MKP-1 phosphatase pathway. J Biol Chem 2012;287:22799-811.

19. Peng Y, Chen Q, Gu M, et al. Human Stromal Cells in the Peripheral Zone of the Prostate Promote Tumorigenesis of Prostatic Cancer Stem Cells through Up-regulation of C-Kit Expression. J Cancer 2015;6:776-85.

20. Redondo-Castro E, Faust D, Fox S, et al. Development of a characterised tool kit for the interrogation of NLRP3 inflammasome-dependent responses. Sci Rep 2018;8:5667.

21. Jain A, Kaczanowska S, Davila E. IL-1 ReceptorAssociated Kinase Signaling and Its Role in Inflammation, 
Cancer Progression, and Therapy Resistance. Front Immunol 2014;5:553.

22. Butler DSC, Ambite I, Nagy K, et al. Neuroepithelial control of mucosal inflammation in acute cystitis. Sci Rep

Cite this article as: Sun J, Xia L, Peng Y. Loss of NLRP3 increases bacterial cystitis via IRAKM. Transl Androl Urol 2022;11(2):268-276. doi: 10.21037/tau-22-67
$2018 ; 8: 11015$.

(English Language Editor: C. Betlazar-Maseh) 